\title{
Metal triflates for the production of aromatics from lignin
}

\author{
Peter J. Deuss, ${ }^{[a]}$ Ciaran W. Lahive, ${ }^{[b]}$ Christopher S. Lancefield, ${ }^{[b]}$ N. J. Westwood, ${ }^{[b]}$ Paul C. J. \\ Kamer $^{[b]}{ }^{[b]}$ Katalin Barta*[a] and Johannes G. de Vries ${ }^{*[a][c]}$
}

\begin{abstract}
The depolymerization of lignin into valuable aromatic chemicals is one of the key goals towards establishing economically viable biorefineries. In this contribution we present a simple approach for converting lignin to aromatic monomers in high yields, under mild reaction conditions. The methodology relies on the use of catalytic amounts of easy to handle metal triflates. Initially, we evaluated the reactivity of a broad range of metal triflates using simple lignin model compounds. More advanced lignin model compounds were also used to study the reactivity of different lignin linkages. The product aromatic monomers were either phenolic $\mathrm{C} 2$ acetals obtained by stabilization of the aldehyde cleavage products by reaction with ethylene glycol, or methyl aromatics obtained by catalytic decarbonylation. Notably, when the former method was ultimately tested on lignin, especially $\mathrm{Fe}(\mathrm{OTf})_{3}$ proved very effective and the phenolic $\mathrm{C} 2$ acetal products were obtained in an excellent, $19.3 \pm 3.2 \mathrm{Wt} \%$ yield.
\end{abstract}

\section{Introduction}

The development of fundamentally new catalytic methods is of central importance for the production of bulk and fine chemicals from renewable lignocellulose feedstocks.[1][2] In this context, it is very important to valorize all main constituents of lignocellulose, including lignin.[3] However, despite recent efforts, the catalytic conversion of lignin has proven very challenging.[4] Acidolysis is an efficient method for the cleavage of the most abundant, $\beta-O-4$ linkage in lignin (Scheme 1).[5] In addition, acid catalyzed depolymerization is a highly relevant method especially in relation to the future biorefinery concept, since the most common organosolv lignin extraction methodologies also use acidic media.[6] One of the main challenges with acid mediated degradation of lignin is the reconstitution of reactive fragments leading to more robust oligomeric structures often referred to as biochar. In essence, acidolysis leads to phenolic C2-

[a] Dr. P. J.Deuss, Dr. K. Barta, Prof. J. G. de Vries Stratingh Institute for Chemistry,

University of Groningen Department

Nijenborgh 4, 9747 AG, Groningen, The Netherlands

E-mail: k.barta@rug.nl, i.g.devries@rug.nl

[b] C. W. Lahive, Dr. C. S. Lancefield, Prof. N. J. Westwood, Prof. P. C. J. Kamer

School of Chemistry and Biomedical Science Research Complex University of St Andrews and EaStCHEM

North Haugh, St Andrews, Fife, KY16 9ST, United Kingdom

[c] Prof. J. G. de Vries

Leibniz-Insitut für Katalyse e.V. and der Universität Rostock

Albert-Einstein-Straße 29a, 18059 Rostock, Germany

E-mail: johannes.deVries@catalysis.de

Supporting information for this article is given via a link at the end of the document.((Please delete this text if not appropriate)) acetaldehydes that are notoriously unstable under acidic conditions. This is the major reason why this acidolysis pathway has largely escaped attention for the production of aromatic monomers from lignin until recently. In new studies by our group and others, it was shown that by capturing these reactive intermediates formed upon acidolysis, lignin can be effectively depolymerized with suppression of recondensation pathways leading to improved monomer yields (Scheme 1b).[7]

Of the different in situ stabilization methodologies applied, in particular, acetal formation with ethylene glycol led to a defined set of major products in good yields from models and lignin. The cleavage of the $\beta-O-4$ linkage was most efficiently promoted by strong acids with non-coordinating anions such as triflic acid (HOTf).[7a,d] However, HOTf is corrosive and inconvenient to handle, which may lead to inconsistent results. On the other hand, metal triflates are weighable solids that are less corrosive than HOTf and therefore much less hazardous in handling.[8]

Additionally, in the case of other homogeneous catalyst used, for example in the iridium-catalyzed decarbonylation to give $p$-cresol and mono- and di-methoxylated cresols, the strongly acidic conditions may affect the stability of the iridium catalyst.[7a] For this reason, we were interested to assess the usefulness of Lewis acids such as metal triflates and their compatibility with the homogeneous metal catalysts used.

In this contribution, we evaluate the reactivity of different metal triflate salts for the cleavage of $\beta-0-4$ linked as well as $\beta-5$ and $\beta$ $\beta$ lignin model compounds. We determine the quantities of ethylene glycol acetals or methyl-aromatics obtained after stabilization of reactive intermediates by acetal formation or decarbonylation, upon bond cleavage. Ultimately, the depolymerization of walnut methanosolv lignin was successfully carried out and the use of $\mathrm{Fe}(\mathrm{OTf})_{3}$ led to results surpassing those obtained with HOTf.

\section{Results and Discussion}

Metal triflate catalyzed cleavage of $\beta-0-4$ model compound 1 : Acid catalyzed cleavage of the $\beta-O-4$ model compound 1 results in the formation of 2-phenyl acetaldehyde (2) and guaiacol (3) (Scheme 2)[5b,7a-b,9] and 2 is rapidly converted into its aldol condensation products under reaction conditions.[7a,b] After evaluating a range of metal triflates we found that several metal triflates successfully catalyzed the cleavage of $\mathbf{1}$ (Table S2). In toluene (Figure 1a), yields of $\mathbf{3}$ were similar or slightly higher for $\mathrm{Al}(\mathrm{OTf})_{3}, \quad \mathrm{Bi}(\mathrm{OTf})_{3}, \quad \mathrm{Cu}(\mathrm{OTf})_{2}, \quad \mathrm{Eu}(\mathrm{OTf})_{3}, \quad \mathrm{Fe}(\mathrm{OTf})_{3}, \quad \mathrm{Hf}(\mathrm{OTf})_{4}$, $\mathrm{Sc}(\mathrm{OTf})_{3}, \mathrm{Yb}(\mathrm{OTf})_{3}$ when compared to HOTf. No significant reactivity was detected for other metal triflate salts such as AgOTf, $\mathrm{Fe}(\mathrm{OTf})_{2}, \mathrm{Zn}(\mathrm{OTf}) 2$ and $\mathrm{Ni}(\mathrm{OTf})_{2}$. As expected, typically, only small amounts of $\mathbf{2}$ were detected in these reactions in toluene. 
<smiles>[R]c1cc(C(O)C(CO)Oc2c([R])cc(C(O)C(C)CO)cc2[R])cc([R])c1OC(C)C</smiles>

Lignin $\beta-O-4$ linkage<smiles>C=CC=C</smiles>

b)<smiles>[R1]c1ccc(C(O)C([R])Oc2cccc([R])c2)cc1</smiles>

$$
\mathrm{R}^{1}=\mathrm{H}, \mathrm{OMe}
$$

$\mathrm{R}^{2}=\mathrm{H}$ or $\mathrm{CH}_{2} \mathrm{OH}$ or Lignin $\mathrm{R}^{3}=\mathrm{H}, \mathrm{OMe}$

$\begin{gathered}\text { Previously: } \\ \text { HOTf }\end{gathered}$
This work:
M(OTf)

e.g. $M=A l, B i, F e, ~ H f$ $x=1-4$

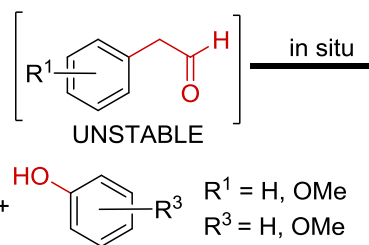<smiles></smiles>

\begin{tabular}{|l|} 
Lignin $\beta-5$ linkage \\
$\mathrm{R}=\mathrm{H}$ or $\mathrm{OMe}$ \\
\hline
\end{tabular}<smiles>[R]c1cc(C2OCC3C(c4cc([R])c(OC)c([R])c4)OCC23)cc([R])c1OC</smiles>

Lignin $\beta-\beta$ linkage

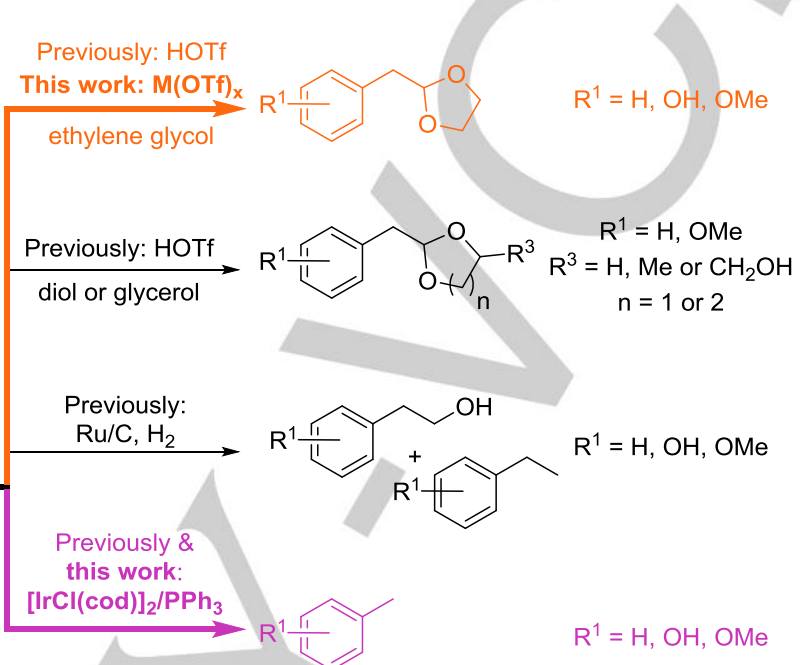

Scheme 1. a) Major linkage motifs in lignin. b) Acid catalyzed cleavage of $\beta-\mathrm{O}-4$ motif in model compounds and lignin with in situ conversion of reactive aldehyde intermediates.

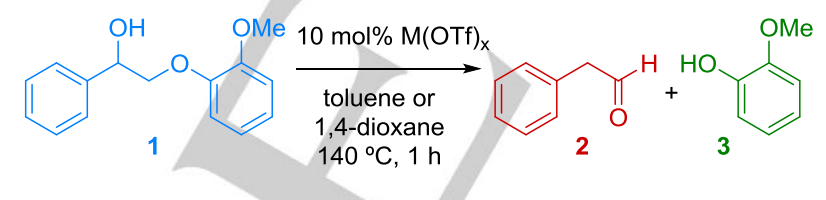

Scheme 2. Metal triflate catalyzed cleavage of lignin $\beta-O-4$ model compound 1.
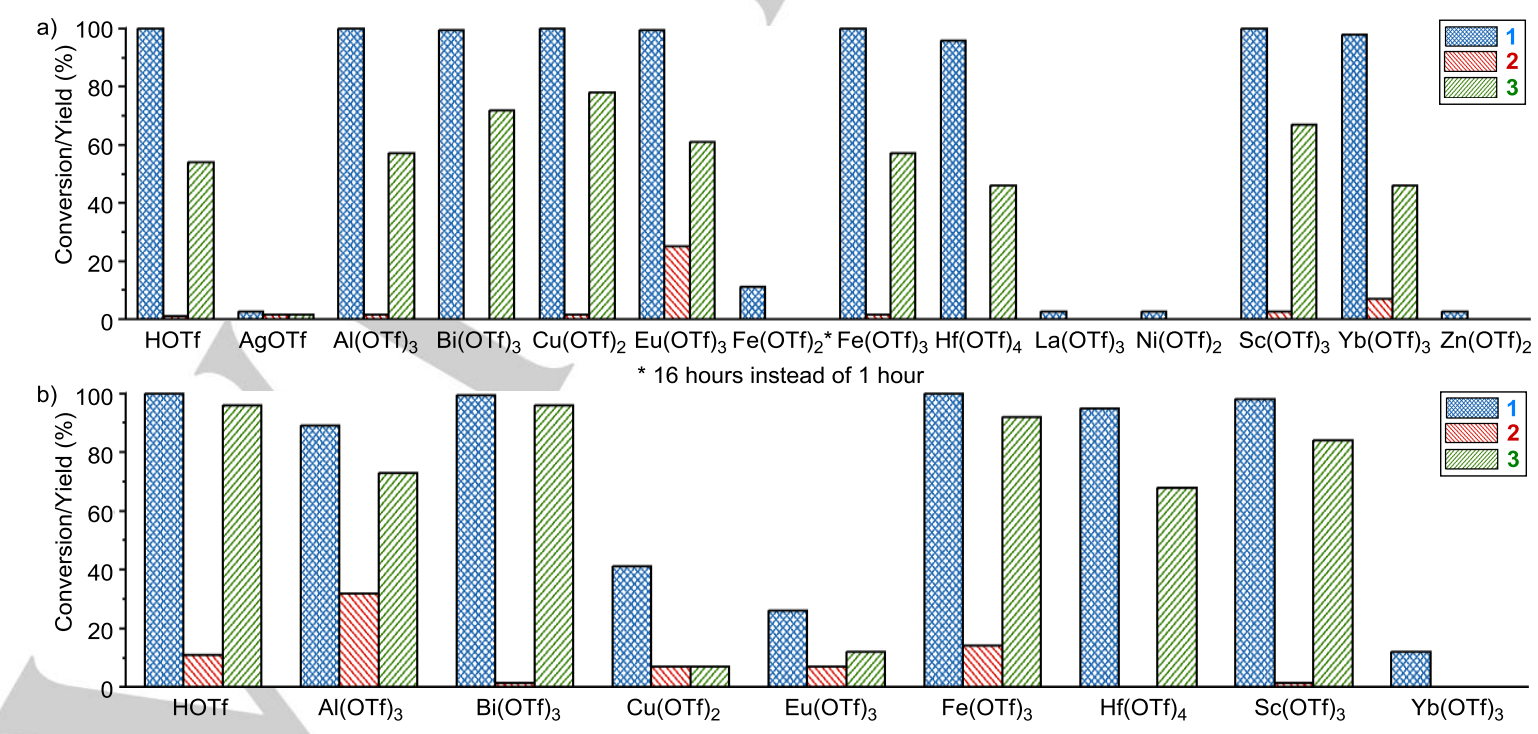

Figure 1. Cleavage of $\beta-0-4$ model compound 1 using metal triflates as catalysts in a) toluene b) 1,4-dioxane (Reaction conditions shown in Scheme 2 ). 
Several metal triflates that showed significant acitivity in toluene were subsequently tested in 1,4-dioxane, which is a suitable solvent for solubilizing lignin (Figure $1 \mathrm{~b}$ ). Here, only $\mathrm{Al}(\mathrm{OTf})_{3}$, $\mathrm{Bi}(\mathrm{OTf})_{3}, \mathrm{Fe}(\mathrm{OTf})_{3}, \mathrm{Hf}(\mathrm{OTf})_{4}$, and $\mathrm{Sc}(\mathrm{OTf})_{3}$ showed good reactivity compared to HOTf. Other metal triflates such as $\mathrm{Cu}(\mathrm{OTf})_{3}$, $\mathrm{Eu}(\mathrm{OTf})_{3}$, and $\mathrm{Yb}(\mathrm{OTf})_{3}$, led to significantly lower conversion of 1 . Overall, higher yields of $\mathbf{2}$ and $\mathbf{3}$ were obtained using 1,4-dioxane as solvent. Indeed, it is well-known that 1,4-dioxane is a Lewis base and can form stable complexes with Lewis acids[10], so it is expected that its use further reduces the acidity of the reaction medium, allowing the formation of substantial quantities of 2 . To evaluate the higher stability of 2 more quantitatively in 1,4-dioxane we monitored the reactions over time using $\mathrm{Fe}(\mathrm{OTf})_{3}$ and HOTf (Figure 2).[7a] The reaction rates and product formation profiles for these reactions showed a remarkably similar pattern, with only slightly higher overall yields of 2 . Additionally, the practical advantage of using the triflate salt compared to HOTf was apparent during this experiment. The metal triflate catalyst could easily be weighed out and added via a stock solution in 1,4dioxane or as a solid to the reaction providing more accurate data compared to experiments that required the addition of microliter quantities of smoking HOTf via microsyringe either directly to the reaction mixture or via a stock solution in the appropriate solvent.

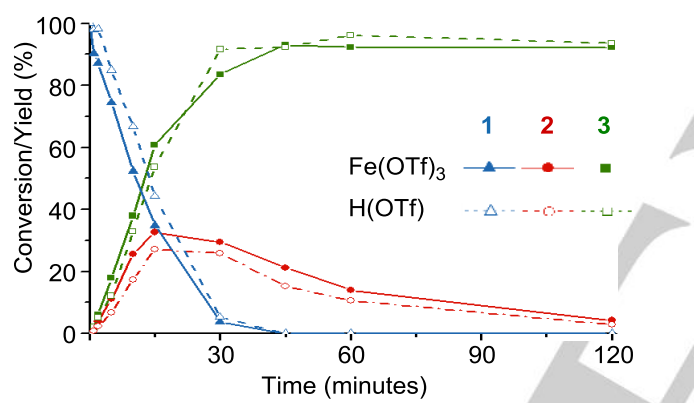

Figure 2. Reaction profiles in the cleavage of 1, using $10 \mathrm{~mol} \% \mathrm{Fe}(\mathrm{OTf})_{3}$ (solid line) and $10 \mathrm{~mol} \% \mathrm{HOTf}$ (dotted line) in 1,4 -dioxane at $140^{\circ} \mathrm{C}$.

All metal triflates that were able to catalyze the cleavage of $\mathbf{1}$ are known to be strong Lewis acids and have already found many applications in organic synthesis.[11] Therefore, the question is whether the cleavage of $\mathbf{1}$ is catalyzed by the metal triflates as Lewis acids, or alternatively, by in situ formation of HOTf from the triflate salts.[12] Other strong Lewis acids like $\mathrm{AlCl}_{3}$ and $\mathrm{FeCl}_{3}$ did not show any significant activity in the cleavage of $\mathbf{1}$ in 1,4dioxane or toluene (Table S2). The addition of non-nucleophilic bases such as 2,6-ditertbutyl-4-methylpyridine[13] or $\mathrm{NaHCO}_{3}$ completely quenched all reactivity for metal triflates that were previously successful in the cleavage of $\mathbf{1}$ (Table S2). These results, combined with the similar reaction progress, led us to conclude that the triflate salts $\left(\mathrm{Al}(\mathrm{OTf})_{3}, \mathrm{Bi}(\mathrm{OTf})_{3}, \mathrm{Cu}(\mathrm{OTf})_{2}\right.$, $\left.\mathrm{Sc}(\mathrm{OTf})_{3}, \mathrm{Fe}(\mathrm{OTf})_{3}, \mathrm{Eu}(\mathrm{OTf})_{3}, \mathrm{Yb}(\mathrm{OTf})_{3}, \mathrm{Hf}(\mathrm{OTf})_{4}\right)$ likely form triflic acid in situ and are therefore capable of catalyzing the acidolysis of 1. Nevertheless, the presence of the metal seems to modulate the acidity somewhat depending on the stability of the triflate salt applied. Remarkably, a good correlation between the conversion of 1 and the hydrolysis constant of several metal triflates were found in both toluene as well as dioxane (displayed in Supporting Information Figure S6, S7).

Metal triflate catalyzed cleavage of $\beta-0-4$ model compounds combined with decarbonylation: After establishing that metal triflates are attractive alternatives to HOTf, we focused on the in situ catalytic decarbonylation of aldehyde 2 towards highly desirable methyl aromatics (Scheme 3).[7a][14] Thus, Fe(OTf) and $\mathrm{Al}(\mathrm{OTf})_{3}$ were tested under decarbonylation conditions using $[\mathrm{IrCl}(\mathrm{cod})]_{2}$ and $\mathrm{PPh}_{3}$ in 1,4-dioxane (Figure 3, Tables S3 and S4).[7a][15] In these reactions, a lower metal triflate loading and milder temperature were used to prevent the build-up of aldehyde 2, which was necessary as the decarbonylation of $\mathbf{2}$ to form toluene 4 catalyzed by $\mathrm{Ir} / \mathrm{PPh}_{3}$ was found to be relatively slow. The results for $\mathrm{Fe}(\mathrm{OTf})_{3}$ and $\mathrm{HOTf}$ at $50 \mathrm{mM}$ substrate concentration and $10 \mathrm{~mol} \%$ catalyst loading were similar. At 25 mM substrate concentration HOTf provided higher conversion of 1 and yield of 3 , whereas $\mathrm{Fe}(\mathrm{OTf})_{3}$ gave slightly better selectivity towards $4(76 \%$ vs $70 \%)$. Using $\mathrm{Al}(\mathrm{OTf})_{3}$ the conversion of 1 and selectivities towards $\mathbf{3}$ and $\mathbf{4}$ were significantly lower. The results of the reactions using $5 \mathrm{~mol} \%$ triflate salt are not strictly comparable, as they were performed for longer time to optimize for product yield. The same trends were observed for a similar $\beta$ O-4 model compound 1c yielding up to $83 \%$ 4c and showing a small increase in decarbonylation efficiency in the presence of $\mathrm{Fe}(\mathrm{OTf})_{3}$ over HOTf (Figure 3, Table S5).

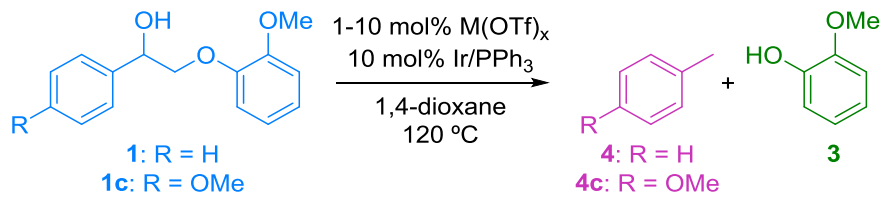

Scheme 3. Metal triflate catalyzed cleavage of lignin $\beta-0-4$ model compound 1 with in situ decarbonylation. 


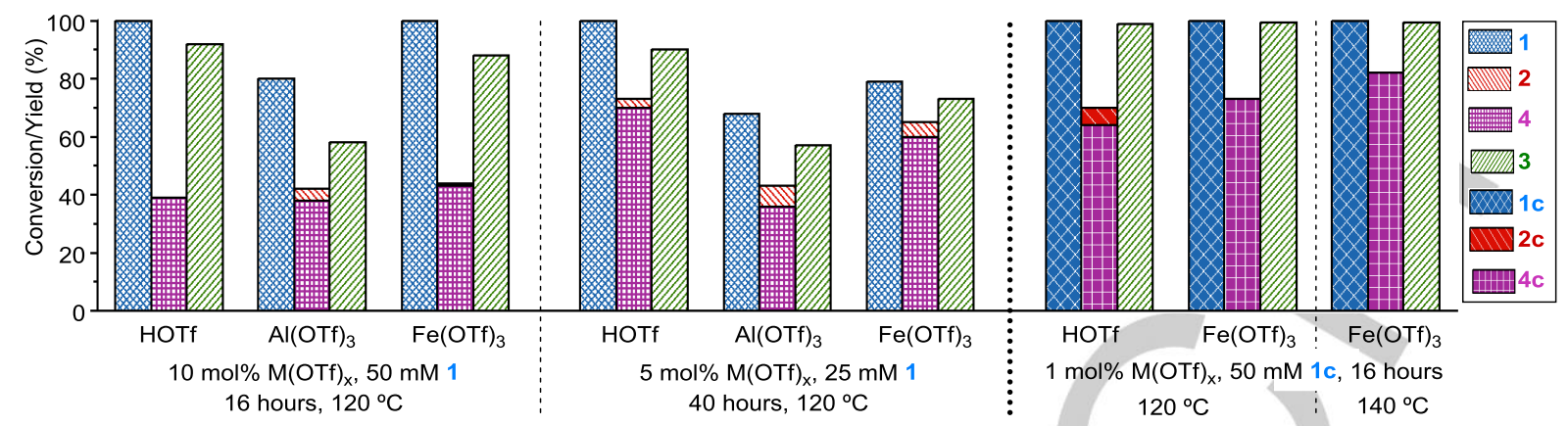

Figure 3. Cleavage of $\beta-\mathrm{O}-4$ model compounds 1 and $\mathbf{1 c}$ catalyzed by metal triflates and in situ decarbonylation of $\mathbf{2}$ and $\mathbf{2 c}$ using $5 \mathrm{~mol} \%[\mathrm{IrCl}(\mathrm{cod})]_{2}$ and $10 \mathrm{~mol} \%$ $\mathrm{PPh}_{3}$.

Metal triflate catalyzed cleavage of $\beta-0-4$ model compounds combined with ethylene glycol acetal formation: Next, we turned our attention to the cleavage of 1 with in situ conversion of the formed aldehyde 2 to its more stable 1,3-dioxolane $\mathbf{5}$ (Scheme 4) using ethylene glycol. Several triflates such as $\mathrm{Bi}(\mathrm{OTf})_{3}$, $\mathrm{Fe}(\mathrm{OTf})_{3}$ and $\mathrm{Hf}(\mathrm{OTf})_{4}$ showed excellent yields of 1,3-dioxolane acetal product 5 and guaiacol 3 (Figure 4 and Table S6). Other triflate salts tested showed significantly lower activity in the presence of ethylene glycol compared to the previous runs in 1,4dioxane alone (compare Figure 4 and Figure 1b). In particular, $\mathrm{Sc}(\mathrm{OTf})_{3}$ showed much lower conversion of $\mathbf{1}$ and only traces of $\mathbf{5}$ with some build-up of $\mathbf{2}$ under these reaction conditions. In a separate set of experiments, we showed that in particular $\mathrm{Sc}(\mathrm{OTf})_{3}$ is relatively inefficient in catalyzing the formation of acetal 5 from 2 and ethylene glycol (Figure S5a).
Next, the reaction profiles for the cleavage of 1 and acetal formation with $\mathrm{Fe}(\mathrm{OTf})_{3}, \mathrm{Hf}(\mathrm{OTf})_{3}$ and $\mathrm{Bi}(\mathrm{OTf})_{3}$ were compared to HOTf (Figure 5). HOTf and $\mathrm{Fe}(\mathrm{OTf})_{3}$ again showed very similar conversion of $\mathbf{1}$ and yields of $\mathbf{3}$ and $\mathbf{5}$ (compare Figures $5 \mathrm{a}$ and $5 b)$. This similarity between $\mathrm{HOTf}$ and $\mathrm{Fe}(\mathrm{OTf})_{3}$ was also observed for reactions in toluene as well as other $\beta-\mathrm{O}-4$ model compounds (1b and 1c Figures S2-4). With 10 mol\% $\mathrm{Hf}(\mathrm{OTf})_{4}$ full substrate conversion was seen, but in this case, within 1 hour and a slight buildup of 2 was observed in the first 15 minutes (Figure 5c). Since aldehyde 2 was already shown to be unstable in the experiments above, this explains the overall lower selectivity of 5 with $\mathrm{Hf}(\mathrm{OTf})_{4}$ as catalyst. The use of $\mathrm{Bi}(\mathrm{OTf})_{3}$ gave slower reactions but similar product yields upon 180 minutes reaction time (Figure $5 \mathrm{~d}$ ). Overall, these reactions showed a clear trend in the rate of cleavage of $1: \mathrm{Hf}(\mathrm{OTf})_{4}>\mathrm{HOTf}=\mathrm{Fe}(\mathrm{OTf})_{3}>\mathrm{Bi}(\mathrm{OTf})_{3}$.

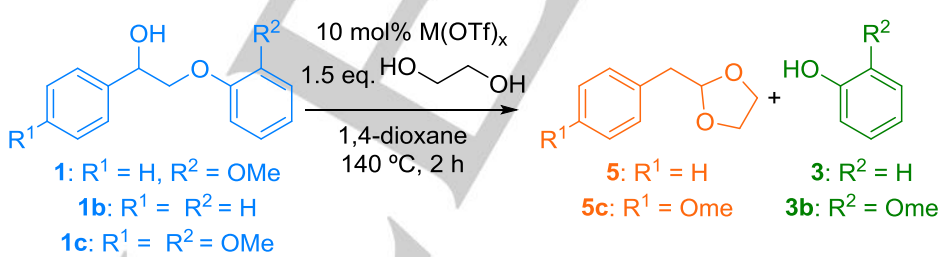

Scheme 4. Cleavage of lignin $\beta-O-4$ model compounds $1,1 b$ and $1 c$ in the presence of ethylene glycol to form 5 and $5 c$ catalyzed by $M(O T f) x$.

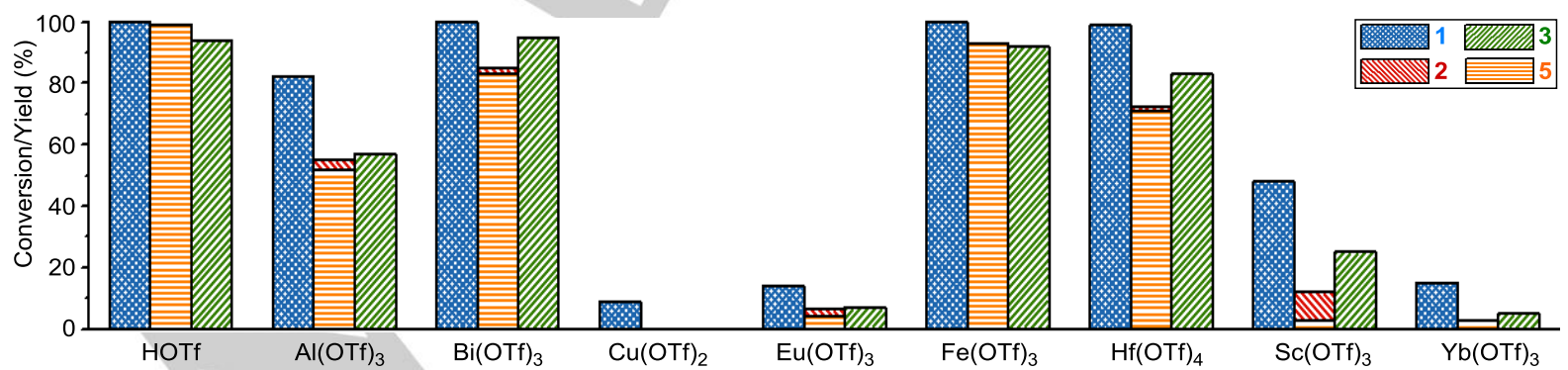

Figure 4. Cleavage of $\beta-\mathrm{O}-4$ model compound 1 using metal triflate catalysts. Reaction conditions shown in Scheme 4 . (Slightly different results were obtained with $\mathrm{Fe}(\mathrm{OTf})_{3}$ from different commercial sources, see Table S1). 

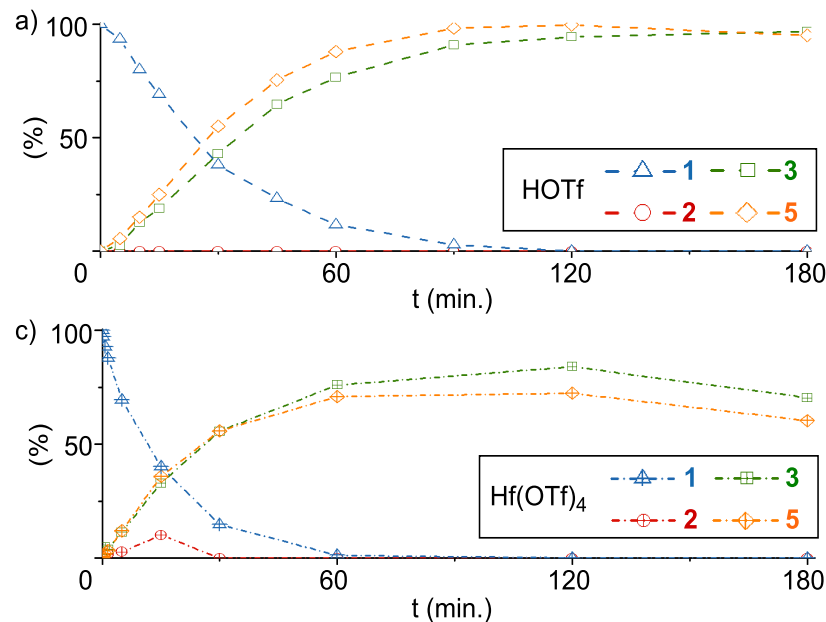

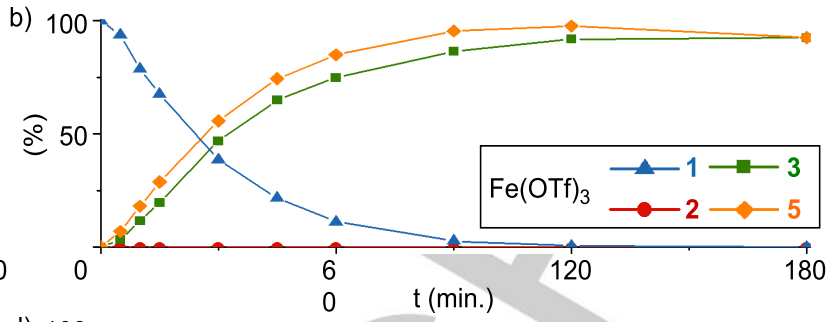

d) 1007

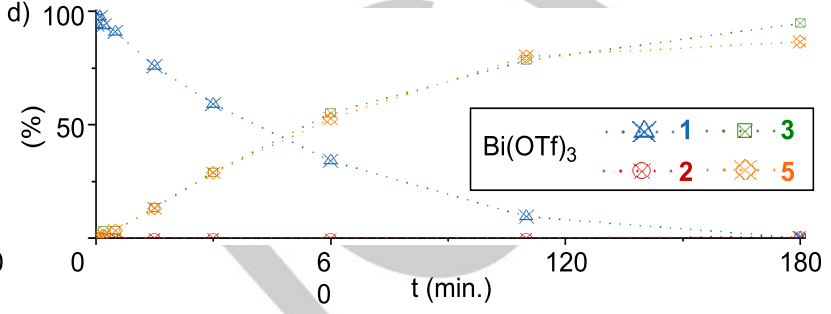

Figure 5. Reaction progress of the cleavage of 1 and in situ acetal formation with ethylene glycol catalyzed by a) 10 mol\% $\mathrm{HOTf}$, b) 10 mol\% Fe(OTf) 3 , c) 10 mol\% $\mathrm{Hf}(\mathrm{OTf})_{4}$ and d) $10 \mathrm{~mol} \% \mathrm{Bi}(\mathrm{OTf})_{3}$.

The reactivity of advanced lignin $\beta-0-4, \beta-5$ and $\beta-\beta$ model compounds: Next, we turned our attention to the reactivity of a more complex $\beta-O-4$ motif containing all functionalities (carbinolgroup and additional electron donating aromatic ring substituents) as well as other types of lignin linkages $(\beta-5$ and $\beta-\beta)$ in the presence of metal triflates. For this purpose, we used a set of advanced lignin model compounds, previously developed and employed by our groups for mechanistic investigations.[7d] These compounds contain $\beta-O-4(6,8$ and 9), $\beta-5$ (7) and $\beta-\beta$ (10) linkages comprising relevant functional groups that reflect the structure of these linkages in lignin (Scheme 5). Model compounds of this level of complexity are rarely used due to limited accessibility and analytical challenges associated with product analysis. Herein we have a unique opportunity to gain more detailed insight into the effectiveness of the methodology employed prior to testing on lignin.[7d]

Model compounds 6-10 were exposed to the cleavage and in situ acetal formation conditions in the presence of $\mathrm{Fe}(\mathrm{OTf})_{3}$ (Scheme 5). The $\beta$-O-4 linkages in compounds $\mathbf{6 , 8}$ and $\mathbf{9}$ were fully cleaved within 15 minutes and provided the corresponding phenolic product 3 in high yields as determined by HPLC (Scheme 5a and c). The ethylene glycol acetals 11,13 and 14 of the corresponding $\mathrm{C} 2$-aldehydes were detected as major cleavage products, albeit at lower yields. This is due to a competing cleavage pathway that leads to $\mathrm{C} 3$ aromatic products that relate to the so-called Hibbert ketones detected in traditional acidolysis reaction mixtures (Figure 6).[5c,16] It was also shown that the $\beta$ 5 linkage in 7-9 undergoes ring-opening to ultimately form the corresponding trans-stilbenes $\mathbf{1 2 - 1 4}$ as major product (Scheme $5 b$ and $c$ ). The product yields indicate a preference for the cleavage of the $\beta-O-4$ moiety via a pathway that releases the carbinol group as formaldehyde. The $\beta-5$ linkage is almost exclusively modified via a similar mechanism.[17] This also means, that the formaldehyde released during these reactions is probably trapped in the form of its ethylene-glycol acetal 1,3dioxolane as also confirmed in our earlier studies.[7d]

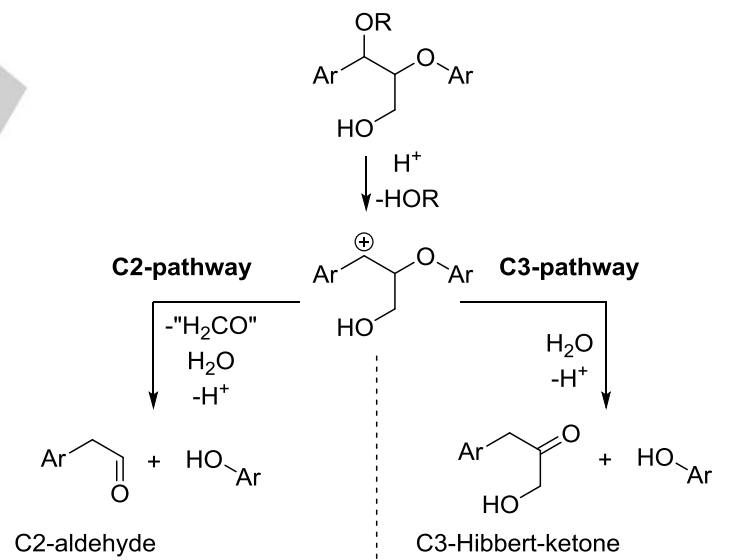

Figure 6. Competing " $\mathrm{C} 2$ " and " $\mathrm{C} 3$ " $\beta-\mathrm{O}-4$ cleavage pathways after formation of the benzylic carbocation. 
<smiles>COc1ccc(C(O)C(CO)Oc2ccccc2OC)cc1OC</smiles>$$
6
$$<smiles>COc1ccc(C2Oc3c(OC)cc(CCCO)cc3[C@@H]2CO)cc1OC</smiles>

c) $\beta-5$ linkage and $\beta-O-4$ linkage

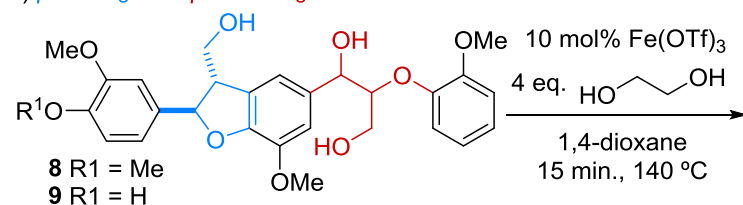

$10 \mathrm{~mol} \% \mathrm{Fe}(\mathrm{OTf})_{3}$

$$
4 \text { eq. } \mathrm{HO} \sim \mathrm{OH}
$$

1,4-dioxane 15 min., $140^{\circ} \mathrm{C}$ 1,4-dioxane

15 min., $140^{\circ} \mathrm{C}$

$\beta-\beta$ linkage<smiles>OCCO[Mg]O[Mg]</smiles><smiles>COc1cc(CC2OCCO2)cc([AsH3+])c1OC</smiles><smiles>COc1cc(O)cc(C=[18O])c1</smiles><smiles>COc1cc(/C=C/c2cc(CCCO)cc(OC)c2O)ccc1[18O]</smiles>

$12(87 \%)$

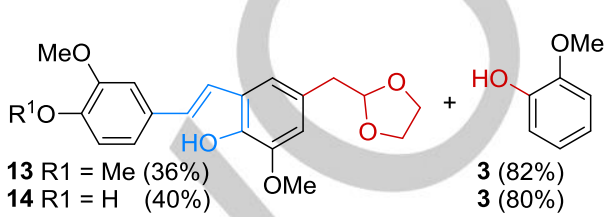

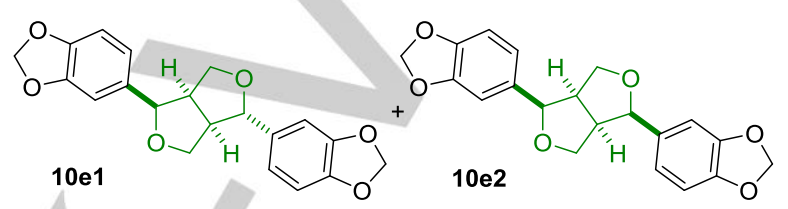

$10: 10 \mathrm{e} 1: \mathbf{1 0 e 2}=1: 1: 0.1(>95 \%$ total yield GC)

Scheme 5. Reaction of a) Complex $\beta-0-4$ model compound 6 , b) $\beta-5$ model compound 7, c) Advanced $\beta-0-4-\beta-5$ model compounds 8 and 9, d) $\beta-\beta$ model compound 10. Reaction conditions: $10 \mathrm{~mol} \% \mathrm{Fe}(\mathrm{OTf})_{3}$, ethylene glycol, in 1,4-dioxane.
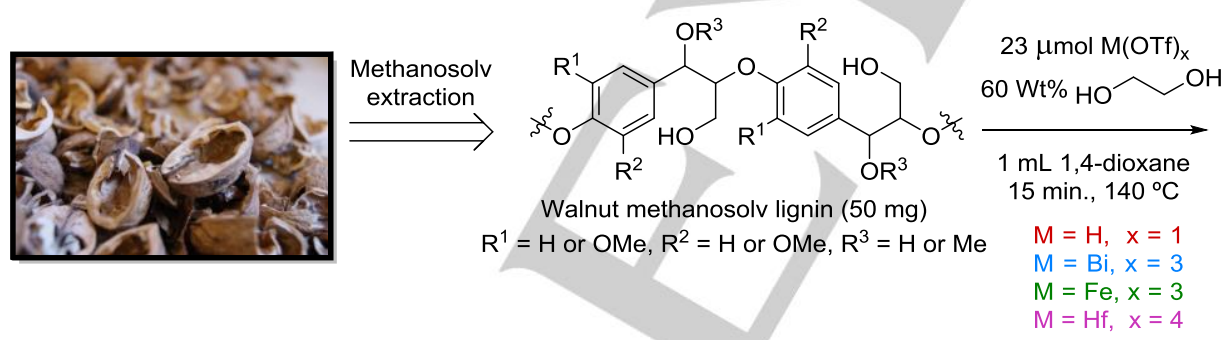

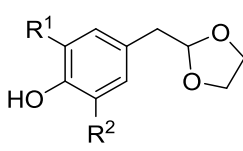

P1 $\mathrm{R}^{1}=\mathrm{R}^{2}=\mathrm{H}$

P2 $\mathrm{R}^{1}=\mathrm{OMe}, \mathrm{R}^{2}=\mathrm{H}$

P3 $R^{1}=R^{2}=O M e$

Scheme 5. Metal triflate catalyzed depolymerization of walnut methanosolv lignin (representive structure shown) in the presence of ethylene glycol to give acetal phenols P1-3.

The $\beta-\beta$ model compound $\mathbf{1 0}$ showed epimerization upon reaction with $\mathrm{Fe}(\mathrm{OTf})_{3}$ in the presence of ethylene glycol forming a mixture of epimers $10: 10 \mathrm{e} 1: 10 \mathrm{e} 2$ of $1: 1: 0.1$ as determined by GCFID (Scheme 5d). We have previously obtained the same results with $10 \mathrm{~mol} \%$ HOTf as catalyst.[7d] Overall, it can be concluded that a very similar reactivity was observed for the advanced model compounds 6-10 both in the presence of $\mathrm{Fe}(\mathrm{OTf})_{3}$ and HOTf. Regarding the different types of linkages, the $\beta-0-4$ linkage model compounds were efficiently cleaved to two aromatic monomers (acetal and phenol product), however the $\beta-5$ and $\beta-\beta$ linkage models resulted in the formation of modified aromatic dimers. This means that applying these methods using lignin as substrate, only the scission of the $\beta-0-4$ moiety will allow for depolymerization. This highlights the importance of having a high $\beta-O-4$ content in the lignin used in order to achieve high aromatic monomer yields using the presented methodology.
Metal triflate catalyzed depolymerization of walnut methanosolv lignin: Finally, after studying the reactivity of all main types of linkages, the metal triflates $\mathrm{Bi}(\mathrm{OTf})_{3}, \mathrm{Fe}(\mathrm{OTf})_{3}$ and $\mathrm{Hf}(\mathrm{OTf})_{4}$ that showed the most promising results in the model compound studies were tested in lignin depolymerization in the presence of ethylene glycol. The results were compared to those obtained with HOTf (Scheme 5). For these reactions, methanosolv walnut lignin was isolated from walnut shells. This lignin has a higher $\beta-O-4$ content $(26 \beta-O-4$ linkage per 100 aromatic units) compared to other organosolv lignin tested previously by our group.[7a,d] The very simple catalytic methodology consisted of runs using $50 \mathrm{mg}$ lignin, $60 \mathrm{Wt} \%$ ethylene glycol and catalytic amounts of $\mathrm{M}(\mathrm{OTf})_{\mathrm{x}}$ at $140^{\circ} \mathrm{C}$ for 15 minutes in 1,4-dioxane. The depolymerization mixtures were subjected to a fractionation procedure, in which the low-molecular weight material was extracted using toluene (Table S7).

To evaluate the effectiveness of the metal triflate catalysts, we focused on the major monomeric products P1-P3 which were 
quantified by GC-FID using an internal standard (Figure 7, Table S8). The ratio of $\mathbf{P 1}: \mathbf{P 2}: \mathbf{P} 3$ was found to be $4: 33: 63$ for all experiments, in almost perfect agreement with the $H: G: S$ ratio of $6: 29: 65$ determined by 2D-HSQC NMR analysis of the starting lignin.[7d] Overall, excellent yields of P1-3 were obtained, reaching over $10 \mathrm{Wt} \%$ for all metal triflate catalyzed reactions. Interestingly, $\mathrm{Fe}(\mathrm{OTf})_{3}$ performed better than the other triflates and HOTf, reaching an excellent yield of P1-3 of $19.3 \pm 3.2 \mathrm{Wt} \%$. Thus far, only a few reports exist with such high yields of aromatic monomers, especially of product mixtures with limited complexity [3a-d][18], thus this method further contributes to achieving the highly efficient valorization of renewable resources and the production of distinct valuable monomers in high yields. [19]

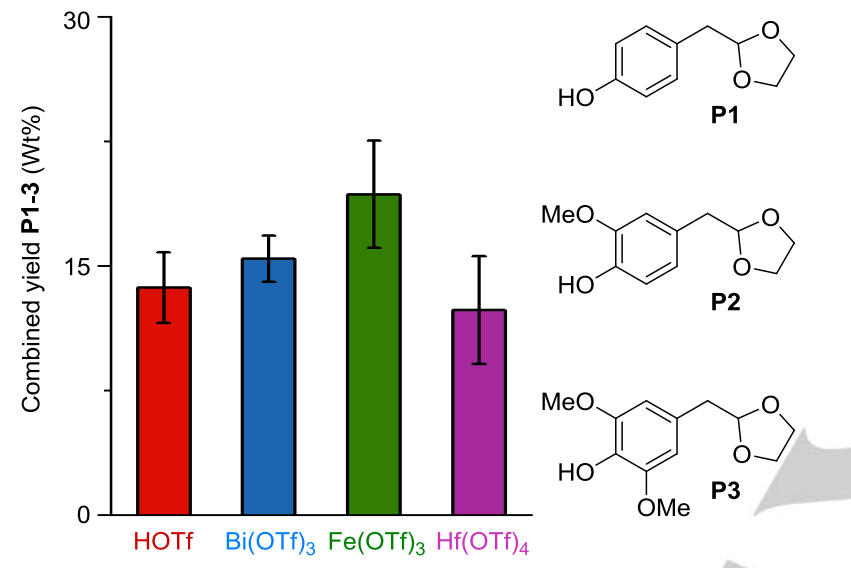

Figure 7. Yields of P1-3 after depolymerization of $50 \mathrm{mg}$ walnut methanosolv lignin with $23 \mu \mathrm{mol} \mathrm{M}(\mathrm{OTf})_{\mathrm{n}}$ in $1 \mathrm{~mL}$ 1,4-dioxane with 60 wt\% ethylene glycol for 15 minutes at $140{ }^{\circ} \mathrm{C}$ (Shown data are averages of 2-3 identical experiments).

\section{Conclusions}

Overall, this study shows that several metal triflates can be excellent substitutes for HOTf in the depolymerization of lignin. The general reactivities of lignin model compounds compare well to those observed with triflic acid, and preliminary studies suggest that the in situ formed triflic acid is responsible for the reactivity of these metal triflates. While model compounds mirroring all three major lignin linkages $(\beta-O-4, \beta-\beta, \beta-5)$ show similar behavior in the presence of triflates and triflic acid, there are variations in substrate conversion and product yields depending on the type of metal triflate used. For example, $\mathrm{Hf}(\mathrm{OTf})_{4}$ shows higher activity for the cleavage of $\beta-O-4$ model compounds but lower product selectivity, while other triflate salts such as $\mathrm{Bi}(\mathrm{OTf})_{3}$ showed lower activity but similar selectivities. In the depolymerization of organosolv lignin, $\mathrm{Bi}(\mathrm{OTf})_{3}, \mathrm{Fe}(\mathrm{OTf})_{3}$ and $\mathrm{Hf}(\mathrm{OTf})_{4}$ all showed promising results and three main aromatic products $\mathbf{P 1 - 3}$ were clearly identified as major products. Interestingly, the best aromatic monomer yields of $19.3 \pm 3.2 \mathrm{Wt} \%$ were obtained with $\mathrm{Fe}(\mathrm{OTf})_{3}$, reflecting differences in reactivity in this case in favor of the metal triflate compared to triflic acid. More specific reasons for this behavior are currently being investigated in our laboratories. Future studies should also address the possibility of catalyst recycling either by immobilization of the triflate salts [21a] or HOTf [21b].

\section{Experimental Section}

Metal triflate catalyzed cleavage of $\beta-0-4$ model compounds: Substrate (e.g. 1, $48.9 \mathrm{mg}, 0.2 \mathrm{mmol}$ ) was weighed out in a $20 \mathrm{ml}$ microwave vial, equipped with a magnetic stirring bar. Solvent (e.g. 1,4dioxane, $2 \mathrm{~mL}$ ) and n-octadecane ( $25 \mu \mathrm{mol}$ from a $0.25 \mathrm{M}$ stock solution in the appropriate solvent) were added and the vial was sealed. The solution was stirred and heated to the appropriate temperature and the catalyst (e.g. triflic acid, $10 \mathrm{~mol} \%, 1 \mu \mathrm{L}, 0.02 \mathrm{mmol}$ or $200 \mu \mathrm{L}$ of a freshly prepared $5 \mathrm{mg} / \mathrm{mL} \mathrm{Fe}(\mathrm{OTf})_{3}$ stock in 1,4-dioxane, $10 \mathrm{~mol} \%, 0.02 \mathrm{mmol}$ ) was added by syringe with a thin needle through the septum of the microwave vial. If samples were taken, this was done by syringe equipped with a long thin needle. The samples (100-150 $\mu \mathrm{L})$ were filtered, diluted in DCM and analyzed by GCFID and GCMS (Figure 2). Otherwise the reaction was stopped by cooling on ice. The crude reaction mixture was filtered over celite and an aliquot was taken for GCFID and GCMS analysis (Table S2). Leaching test was performed to determine the residual metals in the product phase (Supporting Information, $\mathrm{XY}$ )

Metal triflate catalyzed cleavage of $\beta-0-4$ model compounds in combination with in situ decarbonylation: Inside a glovebox a $20 \mathrm{~mL}$ microwave vial was charged with substrate (e.g. 1, $12.2 \mathrm{mg}, 0.05 \mathrm{mmol}$ ) and $n$-octadecane $(6,25 \mu \mathrm{mol})$ from a stock solution in 1,4-dioxane. A premixed solution of $\mathrm{PPh}_{3}$ and $[\mathrm{IrCl}(\mathrm{cod})]_{2}$ in 1,4-dioxane (mixed for 15 minutes prior to addition) was added to this mixture and the vial was sealed. The vial was stirred and heated to the appropriate temperature and catalyst from a stock solution in 1,4-dioxane was added by syringe with a thin needle through the septum of the microwave vial. Upon completion the reaction mixtures were cooled on ice and filtered over celite. Aliquots of the reaction mixtures were diluted in DCM and analyzed by GCFID and GCMS (Results in Table S3-5).

Metal triflate catalyzed cleavage of $\beta-0-4$ model compounds in combination with in situ acetal formation: Substrate (e.g. 1, $48.9 \mathrm{mg}$, $0.2 \mathrm{mmol}$ ) was weighed out in a $20 \mathrm{~mL}$ microwave vial, equipped with a stirring bar. Solvent (e.g. 1,4- dioxane, $2 \mathrm{~mL})$ and n-octadecane $(25 \mu \mathrm{mol}$ from a $0.25 \mathrm{M}$ stock solution in the appropriate solvent), diol (e.g. ethylene glycol $16 \mu \mathrm{L} 0.3 \mathrm{mmol}$ ) were added and the vial was sealed. The solution was stirred and heated to the appropriate temperature and catalyst (e.g. triflic acid, $10 \mathrm{~mol} \%, 1 \mu \mathrm{L}, 0.02 \mathrm{mmol}$ or $200 \mu \mathrm{L}$ of a freshly prepared 5 $\mathrm{mg} / \mathrm{mL} \mathrm{Fe}(\mathrm{OTf})_{3}$ stock in 1,4-dioxane, $10 \mathrm{~mol} \%, 0.02 \mathrm{mmol}$ ) was added by syringe with a thin needle through the septum of the microwave vial. If samples were taken, this was done by syringe equipped with a long thin needle. The samples (100-150 $\mu \mathrm{L})$ were filtered, diluted in DCM and analyzed by GCFID and GCMS (See Figures 3 \& S2-4). Otherwise the reaction was stopped by cooling on ice. The crude reaction mixture was filtered over celite and an aliquot was taken for GCFID and GCMS analysis (Results in Table S6).

Metal triflate catalyzed depolymerization of walnut methanosolv lignin in combination with in situ acetal formation: Walnut methanosolv lignin $(50 \mathrm{mg})$ isolated by a reported procedure ${ }^{[7 \mathrm{c}]}$ was placed in a $20 \mathrm{~mL}$ microwave vial equipped with a magnetic stirring bar. Solvent (1,4-dioxane, $1 \mathrm{~mL}$ ), internal standard (n-ocatadecane, $10 \mu \mathrm{L}$ from a 0.25 $M$ stock in 1,4-dioxane, $2.5 \mu \mathrm{mol})$ and ethylene glycol $(145 \mu \mathrm{L}$ from a 7.1 $M$ stock in 1,4-dioxane) were added. The catalyst $\mathrm{M}(\mathrm{OTf})_{\mathrm{x}}(23 \mu \mathrm{mol})$ was added as a solid (HOTf was added from a $0.23 \mathrm{M}$ stock solution in 1,4dioxane) and the vial was sealed. The reaction was stirred at $140{ }^{\circ} \mathrm{C}$ for 15 minutes before being cooled rapidly in an ice bath. The mixture was 
filtered over a plug of celite and the flask and filter washed with about $0.5 \mathrm{~mL}$ 1,4-dioxane in 3 portions. The combined filtrate was evaporated to dryness over 16 hours at $40^{\circ} \mathrm{C}$ in a Univapo $150 \mathrm{ECH}$ rotational vacuum concentrator. The residue was suspended in $150 \mu \mathrm{L}$ dichloromethane by extensive mixing (by vortex) after which $1.35 \mathrm{~mL}$ toluene was added. The samples were vortexed and subsequently centrifuged for 10 minutes at 13400 rpm using an Eppendorf minispin tabletop centrifuge. The light organic liquid and solid or thick oily residue were separated. This procedure for suspension/washing with 10\% DCM and $90 \%$ toluene was repeated three times after which both the combined extracted fractions and the residue were dried for 24 hours at $40{ }^{\circ} \mathrm{C}$ in an Univapo $150 \mathrm{ECH}$ rotational vacuum concentrator (dried weights see Table S7). The oil containing the low molecular weight components was dissolved in DCM and analysed by GC-FID for quantification of P1-3 (Table S8).

\section{Acknowledgements}

This work was funded by the European Union (Marie Curie ITN 'SuBiCat' PITN-GA-2013-607044, PJD, CWL, NJW, PCKL, KB, JGdeV) as well as EP/J018139/1, EP/K00445X/1 grants (NJW and PCJK) and an EPSRC Doctoral Prize Fellowship (CSL). Additionally, we would like to acknowledge Dr. A. Narani for his contribution to lignin extraction and T. Yan and M. Scott for their contributions to the synthesis of model compounds $\mathbf{1}, \mathbf{1 b}$ and $\mathbf{1 c}$ as well as Dr. Fanny Tran for the kind gift of compound $\mathbf{1 0 .}$

Keywords: Biomass • Lignin • Cleavage reactions • Acidolysis • Aromatic products

[1] a) C. O. Tuck, E. Pérez, I. T. Horváth, R. A. Sheldon, M. Poliakoff, Science 2012, 337, 695-699; b) P. N. R. Vennestrøm, C. M. Osmundsen, C. H. Christensen, E. Taarning, Angew. Chem. Int. Ed. 2011, 50, 10502-10509

[2] a) M. Besson, P. Gallezot, C. Pinel, Chem. Rev. 2014, 114, 1827-11879; b) P. J. Deuss, K. Barta, J. G. de Vries, Catal. Sci. Technol. 2014, 4 1174-1196; c) A. Ragauskas, G. T. Beckham, M. J. Biddy, R. Chandra F. Chen, M. F. Davis, B. H. Davidson, R. A. Dixon, P. Gilna, M. Keller, P. Langan, A. K. Naskar, J. N. Saddler, T. J. Tschaplinski, G. A. Tuskan, C. E. Wyman, Science 2014, 344, 1246843.

[3] For selected recent examples see: a) A. Rahimi, A. Ulbrich, J. J. Coon S. S. Stahl, Nature 2014, 515, 249-252; b) E. Feghali, G. Carrot, P. Thuéry, C. Genre, T. Cantat, Energy Environ. Sci. 2015, 8, 2734-2743 c) I. Klein, Ch. Marcum, H. Kenttamaa, M. M. Abu-Omar, Green Chem. 2016, 18, 2399-2405; d) S. Van den Bosch, W. Schutyser, R. Vanholme, T. Driessen, S-F. Koelewijn, T. Renders, B. De Meester, W. J. J. Huijgen, W. Dehaen, C. M. Courtin, B. Lagrain, W. Boerjan, B.F. Sels, Energy Environ. Sci., 2015, 8, 1748-1763; e) T. vom Stein, T. den Hartog, J. Buendia, S. Stoychev, J. Mottweiler, C. Bolm, J. Klankermayer, W. Leitner, Angew. Chem. Int. Ed. Engl. 2015, 54, 5859-5863. (f) Dabral, S. Mottweiler, J.; Rinesch, T.; Bolm, C. Green Chem. 2015, 17, 4908-4912.

[4] See recent reviews and references therein: a) C. Xu, R. A. D. Arancon, J. Labidi, R. Luque, Chem. Soc. Rev. 2014, 43, 7485-7500; b) P. J. Deuss, K. Barta, Coord. Chem. Rev. 2016, 306, 510-532; c) S. K. Hanson, R. T. Baker, Acc. Chem. Res. 2015, 48, 2037-2048; d) R Rinaldi, R. Jastrzebski, M. T. Clough, J. Ralph, M. Kennema, P. C. A. Bruijnincx, B. Weckhuysen, Angew. Chem. Int. Ed. 2016, 55, 2 - 54

[5] a) T. Yokoyama, J. Wood Chem. Technol. 2014, 35, 27-42; b) M. R. Sturgeon, S. Kim, K. Lawrence, R. S. Paton, S. C. Chmely, M. Nimlos, T. D. Foust, G. T. Beckham, ACS. Sustainable. Chem. Eng. 2014, 2, 472-485; c) K. Lundquist, Appl. Polym. Symp. 1976, 28, 1393-1407.
[6] For selected references on early work on acidolysis related to organosolv extraction see: a) E. West, A. S. MacInnes, H. Hibbert, J. Am. Chem. Soc. 1943, 65, 1187-1192; b) J. M. Pepper, P. E. T. Baylis, E. Adler, Can. J. Chem, 1959, 37, 1241-1248; c) K. Lundquist, Acta. Chem. Scand. 1973, 27, 2597-2606; Recent selected references on organosolv lignin isolation: d) A. Guerra, I. Filpponen, L. A. Lucia, D. S. Argyropoulos, J. Agric. Food Chem. 2006, 54, 9696-9705; e) S. Bauer, H. Sorek, V. D. Mitchell, A. B. Ibáñez, D. E. Wemmer, J. Agric. Food Chem. 2012, 60 8203-8212; f) R. El Hage, N. Brosse, P. Sannigrahi, A. Ragauskas, Polym. Degrad. Stab. 2010, 95, 997-1003; g) R. El Hage, N. Brosse, P. Sannigrahi, A. Ragauskas, Ind. Eng. Chem. Res. 2009, 48, 8328-8334.

[7] a) P. J. Deuss, M. Scott, F. Tran, N. J. Westwood, J. G. de Vries, K. Barta J. Am. Chem. Soc. 2015, 137, 7456-7467; b) M. Scott, P. J. Deuss, J. G. de Vries, M. H. G. Prechtl, K. Barta, Catal. Sci. Technol., 2016, 6, 1882-1891 c) A. Kaiho, M. Kogo, R. Sakai, K. Saito and T. Watanabe, Green Chem., 2015, 17, 2780-2783; d.) C. W. Lahive, Peter J. Deuss, C. S. Lancefield, Z. Sun, D. B. Cordes, C. M. Young, F. Tran, A. M. Z. Slawin, J. G. de Vries, P. C. J. Kamer, N. J. Westwood, K. Barta, J. Am. Chem. Soc. 2016 accepted.

[8] For the metal triflate salts used in this study the skin corrosive category is set to $1 \mathrm{~b}$ for $\mathrm{Cu}(\mathrm{OTf})_{2}$ and $\mathrm{Al}(\mathrm{OTf})_{3}$, and lower for others compared to 1a for HOTf (ECHA categories). Category 1a indicates acute corrosion. Category $1 \mathrm{~b}$ indicates corrosion after $>3$ minutes of skin contact.

[9] a) O. Karlsson, K. Lundquist, S. Meuller, K. Westlid, Acta Chem. Scand. B, 1988, 42, 48-51; b) T. Yokoyama, Y. Matsumoto, J. Wood Chem. Technol. 2010, 30, 269-282.

[10] a) K. S. Surprenant, Dioxane, Ullmann's Encyclopedia of Industrial Chemistry, Electronic Release, Wiley-VCH Weinheim, 2000; b) J. M. McIntosh,Sulfur Trioxide-1,4-Dioxane. e-EROS Encyclopedia of Reagents for Organic Synthesis, John Wiley \& Sons, 2001.

[11] For examples see: a) S. Kobayashi, M. Sugiura, H. Kitagawa, W. W.-L. Lam, Chem. Rev. 2002, 102, 2227-2302; b) R. Akiyama, S. Kobayashi, Chem. Rev. 2009, 109, 594-642; c) T. Ollevier, Org. Biomol. Chem. 2013, 11, 2740-2755; d) R. Gosh, S. Maiti, J. Mol. Catal. A 2007, 264, 1-8; Selected recent examples: e) H. Ishitani, H. Suzuki, Y. Saito, Y Yamashita, S. Kobayashi, Eur. J. Org. Chem. 2015, 5485-5499; f) K. Mori, K. Kurihara, T. Akiyama, Chem. Commun. 2014, 50, 3729-3731 g) B. Wing, Y. Chen, J. Wang, C.-H. Tung, Z. Xu, J. Org. Chem. 2015 , 80, 12718-12724; h) B. Cacciuttolo, S. Poulain-Martini, E. Duñach, Eur. J. Org. Chem. 2011, 3710-3714

[12] More on this subject: a) S. Kobayashi, S. Nagayama, T. Busujima, J. Am Chem. Soc. 1998, 120, 8287-8288; b) N. Legrave, A. Couhert, S Olivero, J.-R. Desmurs, E. Duñach, Eur. J. Org. Chem. 2012, 901-904; c) T. T. Dang, F. Boeck, L. Hintermann, J. Org. Chem. 2011, 76, 9353-9361.

[13] For an example were the addition of a non-nucleophilic base shuts down metal triflate activity proving in situ acid formation, see: a) T. C. Wabnitz, J.-Q. Yu, J. B. Spencer, Chem. Eur. J. 2004, 10, 484-493; For an example where a non-nucleophilic base does not shut down metal triflate activity hence providing evidence for Lewis acid catalyzed reactions see b) S. Kundal, S. Jalal, K. Paul, U. Jana, Eur. J. Org. Chem. 2015, 5513-5517.

[14] Jastrzebski, PhD Thesis, University of Utrecht (NL), 2016. This thesis was published online while we were preparing this manuscript. Here a similar catalytic cleavage was reported using $\mathrm{Sc}(\mathrm{OTf})_{3}$ and several other water tolerant Lewis acid metal triflate salts. Higher reaction temperatures (175-200 $\stackrel{\circ}{ })$ ) were required for cleavage and $[\mathrm{Rh}(\mathrm{cod}] \mathrm{Cl}]_{2} / \mathrm{dppp}[20]$ was used as decarbonylation catalyst.

[15] T. Iwai, T. Fujihara, Y. Tsuji, Chem. Commun. 2008, 6215-6217.

[16] E. West, A. S. Maclnnes, H. Hibbert, J. Am. Chem. Soc. 1943, 65, 1187-1192.

[17] S. Li, K. Lundquist, Holzforschung 1999, 53,39-43.

[18] a) K. Barta, G. R. Warner, E. S. Beach, P. T. Anastas, Green Chem. 2014, 16, 191-196; b) C. S. Lancefield, O. S. Ojo, F. Tran, N. J. Westwood, Angew. Chem. Int. Ed. 2014, 54, 258-262. 
[19] a) C. Li, X. Zhao, A. Wang, G. W. Huber, T. Zhang, Chem. Rev. 2015,115,11559-11624; b.) I. Delidovich, P. J. C. Hausoul, R. Pfützenreuter, M. Rose, R. Palkovits, Chem. Rev. 2016, 116, 1540-1599.

[20] M. Kreis, A. Palmelund, L. Bunch, R. Madsen, Adv. Synth Catal. 2006, 348, 2148-2154.
[21] a) S. Kobayashi, S. Nagayama, J. Am. Chem. Soc., 1998, 120, 29852986; b) P. N. Liu, F. Xia, Q. W. Wang, Y. J. Ren. J. Q. Chen, Green Chem.,2010,12,1049-1055. 


\section{Entry for the Table of Contents}

\section{FULL PAPER}

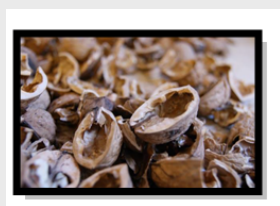

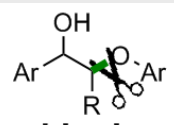

Lignin

$\beta-0-4$ linkage

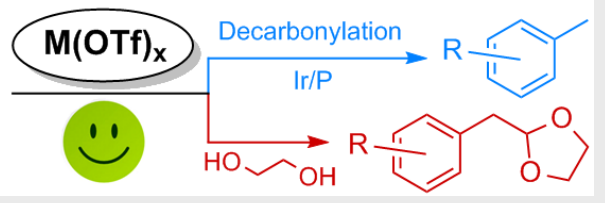

Metal triflates were introduced as an easy to handle alternative to triflic acid for the cleavage of lignin $\beta-O-4$ linkages in conjunction with stabilization of reactive intermediates. The reactivity of several model compounds and lignin was studied. In particular, iron(III) triflate proved effective providing as much as $19.3 \pm 3.2 \mathrm{Wt} \%$ yield of a set of three aromatic C2-acetal from lignin.
P. J. Deuss, C. W. Lahive, C.S. Lancefield, N. J. Westwood, P. C. J. Kamer, K. Barta*, J. G. de Vries*

\section{Page No. - Page No.}

Metal triflates for the production of aromatics from lignin 